\title{
DEPENDENCE OF TOTAL HEMISPHERICAL EMISSIVITY OF INCONEL-718 ON SURFACE OXIDATION AND TEMPERATURE
}

\author{
G.A. Greene and C.C. Finfrock \\ Brookhaven National Laboratory \\ Upton, New York 11973 \\ and \\ T.F. Irvine, Jr. \\ State University of New York at Stony Brook \\ Stony Brook, New York 11794
}

SEPTEMBER 1999

DEPARTMENT OF ADVANCED TECHNOLOGY

Brookhaven National Laboratory

Brookhaven Science Associates

Upton, Long Island, New York 11973

Under Contract No. DE-AC02-98CH10886 with the

UNITED STATES DEPARTMENT OF ENERGY 
BNL-

UC-

DEPENDENCE OF TOTAL HEMISPHERICAL EMISSIVITY OF INCONEL-718 ON SURFACE OXIDATION AND TEMPERATURE

\author{
G.A. Greene and C.C. Finfrock \\ Brookhaven National Laboratory \\ Upton, New York 11973 \\ and \\ T.F. Irvine, Jr. \\ State University of New York at Stony Brook \\ Stony Brook, New York 11794
}

September 1999

Department of Advanced Technology

Brookhaven National Laboratory

Brookhaven Science Associates

Upton, Long Island, New York 11973

Under Contract No. DE-AC02-98CH10886 with the

UNITED STATES DEPARTMENT OF ENERGY 


\title{
DISCLAIMER
}

This report was prepared as an account of work sponsored by an agency of the United States Government. Neither the United States Government nor any agency thereof, nor any of their employees, not any of their contractors, subcontractors, or their employees, makes any warranty, express or implied, or assumes any legal liability or responsibility for the accuracy, completeness, or usefulness of any information, apparatus, product, or process disclosed, or represents that its use would not infringe privately owned rights. Reference herein to any specific commercial product, process or service by trade name, trademark, manufacturer, or otherwise, does not necessarily constitute or imply its endorsement, recommendation, or favoring by the United States Government or any agency, contractor, or subcontractor thereof. The views and opinions of authors expressed herein do not necessarily state or reflect those of the United States Government or any agency, contractor or subcontractor thereof.

\author{
Printed in the United States of America \\ Available from \\ National Technical Information Service \\ U.S. Department of Commerce \\ 5285 Port Royal Road \\ Springfield, VA 22161
}




\begin{abstract}
Total hemispherical emissivities were measured for Inconel-718 as a function of sample temperature. Measurements were made with both unoxidized and oxidized samples. The oxidation temperatures were $1000^{\circ} \mathrm{C}, 1100^{\circ} \mathrm{C}$ and $1142^{\circ} \mathrm{C}$ and the oxidation times were 15,30 and 60 minutes. The oxidized samples showed a significant increase in emissivity over the unoxidized one which was in an "as received" condition. No apparent pattern was observed in the change of emissivity as a function of oxidation time at a given oxidation temperature. In some cases, emissivity measurements made with increasing temperature were greater than those made with descending temperature. One possible explanation for this is the spalling of the oxide layer as the sample area changed (contracted) with descending sample temperature.
\end{abstract}





\section{TABLE OF CONTENTS}

\section{$\underline{\text { Page }}$}

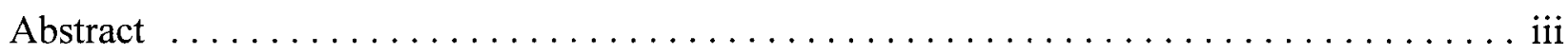

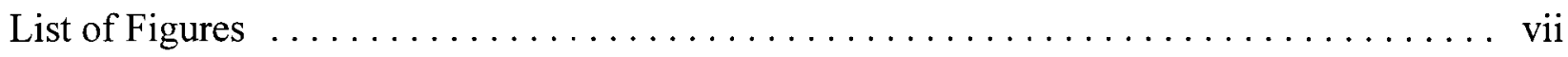

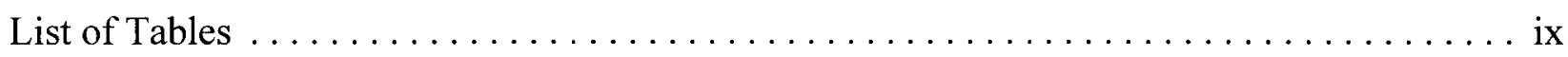

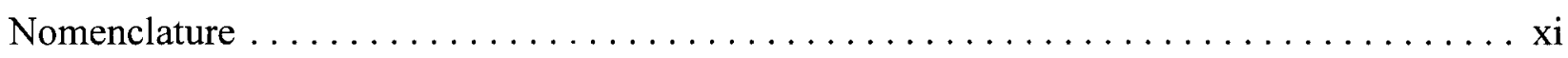

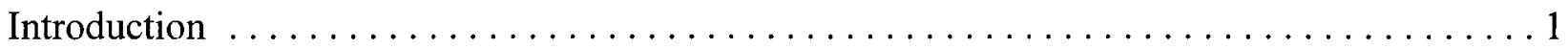

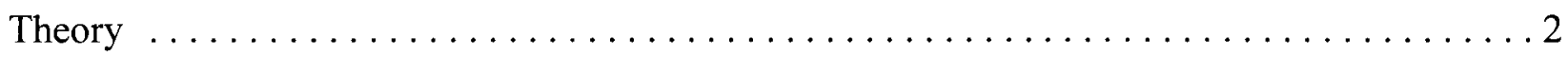

Test Sample Preparation and Experimental Apparatus ......................... 5

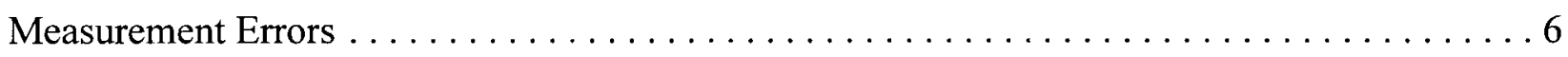

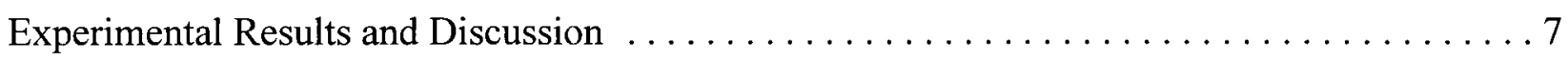

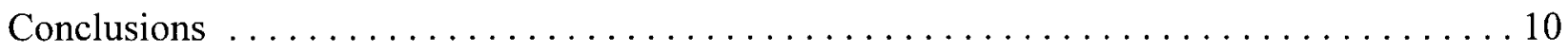

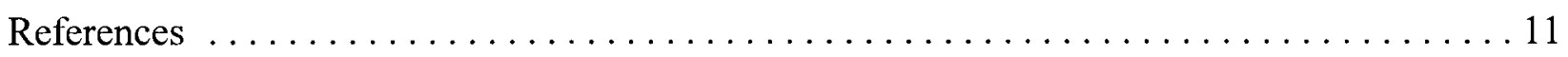




\section{LIST OF FIGURES}

$\underline{\text { Page }}$

Figure $1 \quad$ Variation of Total Hemispherical Emissivity of Inconel with Temperature and Surface Conditions [3]: [A] - As Rolled and Received, [B] - As Received and Oxidized for 15 minutes at $815^{\circ} \mathrm{C},[\mathrm{C}]$ - Sandblasted and Oxidized for 15 Minutes at $815^{\circ} \mathrm{C} \ldots \ldots \ldots 12$

Figure 2 Radiation Between Two Surfaces where $G=$ Irradiation,

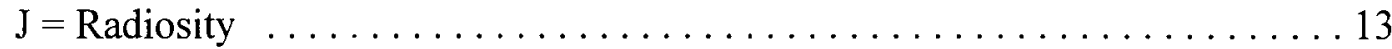

Figure 3 Schematic of Inconel-718 Sample: $\mathrm{x}=$ Thermocouple Wires $\ldots \ldots \ldots 14$

Figure 4 Schematic of Emissivity Measurement System: a- Inconel-718 Sample, b- Enclosure, c- Springs, $x$ - Thermocouple Wires . . . . . . . . . . . . 15

Figure 5 Temperature Difference Between Sample Thermocouple and Reference Thermocouple ...................... 16

Figure 6 Total Hemispherical Emissivity vs. Sample Temperature for Inconel-718 (Non-Oxidized) in As-Rolled Condition . . . . . . . . . . . 17

Figure 7 Total Hemispherical Emissivity vs. Sample Temperature for Inconel-718, Oxidized at $1000^{\circ} \mathrm{C}$ for 15 Minutes [A], 30 Minutes [B],

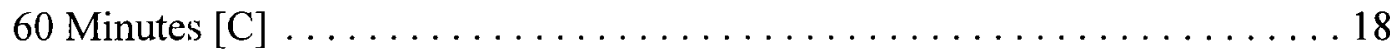

Figure 8 Comparison of Emissivities vs. Sample Temperature for Various Oxidation Times (Oxidized at $\left.1000^{\circ} \mathrm{C}\right)$. . . . . . . . . . . . . . . . . . . . 19

Figure 9 Total Hemispherical Emissivities vs. Sample Temperature for Inconel-718, Oxidized at $1100^{\circ} \mathrm{C}$ for 15 Minutes [A], 30 Minutes [B], 60 Minutes [C]

Figure 10 Total Hemispherical Emissivity vs. Sample Temperature for Inconel-718, Oxidized at $1142^{\circ} \mathrm{C}$ for 15 Minutes [A], 30 Minutes [B], 60 Minutes [C] 


\section{LIST OF TABLES}

$\underline{\text { Page }}$

Table 1 Emissivity Differences With and Without Kirchoff's Law $\ldots \ldots \ldots \ldots \ldots$

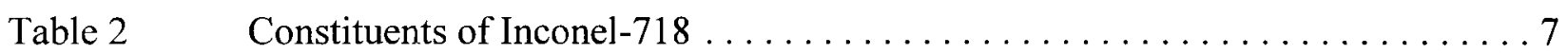

Table 3 Run Numbers for Various Pre-Test Oxidation Times and Temperatures . . . . . 7

Table 4 Maximum Emissivities for Various Pre-Test Oxidation Times and

Temperatures Over the Test Temperature Range up to $1000^{\circ} \mathrm{C} \ldots \ldots \ldots .9$ 


\section{NOMENCLATURE}

\begin{tabular}{|c|c|}
\hline A & Surface Area $\left(\mathrm{m}^{2}\right)$ \\
\hline $\mathrm{E}_{\mathrm{b}}$ & Black Body Radiation $\left(\mathrm{W} / \mathrm{m}^{2}\right)$ \\
\hline $\mathrm{F}$ & Angle Factor (-) \\
\hline G & Irradiation $\left(\mathrm{W} / \mathrm{m}^{2}\right)$ \\
\hline $\mathrm{i}$ & Current (amps) \\
\hline $\mathrm{J}$ & Radiosity (W/m²) \\
\hline$\ell$ & Sample Length (m) \\
\hline Q & Radiation Heat Flow (W) \\
\hline $\mathrm{R}$ & Electric Resistance (ohms) \\
\hline $\mathrm{V}$ & Voltage (volts) \\
\hline w & Sample Width (m) \\
\hline$\alpha$ & Absorptivity (-) \\
\hline$\Delta$ & Increment (-) \\
\hline$\epsilon$ & Emissivity (-) \\
\hline$\sigma$ & Stefan-Boltzman Constant $\left(\mathrm{W} / \mathrm{m}^{2} \mathrm{~K}^{4}\right)$ \\
\hline 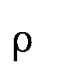 & Reflectivity (-) \\
\hline
\end{tabular}




\section{INTRODUCTION}

Heat transfer in high vacuum systems occurs primarily by thermal radiation. In order to calculate such radiation transfers, it is necessary to know the radiation properties of the surfaces which are emitting and absorbing radiation. In general, these properties must be determined experimentally and the surface properties of the test materials must be as close as possible to those under actual operating conditions.

Unfortunately, such measurements are not always simple to accomplish, particularly when the surface properties change with time as is often the case. Thus, one must make radiation property measurements over a range of surface conditions to attempt to bracket these property values and to better understand their influence on the radiation heat transfer processes.

The present investigation considers thermal radiation heat transfer under vacuum conditions where the radiating and absorbing surfaces are Inconel-718. The purpose for this research was to develop highly precise data of the total hemispherical emissivity of oxidized Inconel-718 for application to the analyses of accident conditions in the APT (Accelerator Production of Tritium ) spallation target under conditions in which the target clad material is simultaneously oxidized and overheated to high temperatures. Due to the tight packing of the nested tungsten cylinders in the APT target, decay heat which is generated in the tungsten can only be transferred from an overheated and dried out target assembly radially outward by thermal radiative heat transfer. The crucial parameter in calculating the peak temperatures in the target during such thermal transients is the radiative emissivity of the Inconel-718 which clads the tungsten target components. Radiation heat transfer accident calculations can only be as accurate and precise as the values of the radiative emissivity that go into the calculations; using emissivities which are either too low or too high will drive the calculated peak temperatures to extremes which renders parametric calculations of little value. Best-estimate accident calculations require precise and accurate thermal radiative emissivity data. A search of the literature failed to find any previous measurements of the radiation properties of this material which would be useful for the present APT application [1-3]. Of particular interest are the effects of surface oxidation and temperature on the emissivity. Therefore, the present investigation was conducted, the purpose of which was the measurement of total hemispherical emissivities over a range of temperatures $\left(200 \leq \mathrm{T} \leq 1000^{\circ} \mathrm{C}\right)$ and a variety of surface oxidation conditions.

The above discussion can be illustrated by reference to Figure 1 from [3]. In the figure are measured total hemispherical emissivities under a variety of surface and temperature conditions. It is seen first of all that the emissivities increase with temperature under all surface conditions. In addition, Curve A whose surface is in the "as rolled" condition has the lowest emissivity of the three samples. Curve $\mathrm{B}$ which is in the "as rolled" condition but which has been oxidized in air at a temperature of $815^{\circ} \mathrm{C}$ for 15 minutes has a significantly larger emissivity than Curve A. Finally, Curve $\mathrm{C}$ which has been sand blasted to increase its surface roughness and also oxidized has the largest emissivities of all three samples. That these differences are significant is illustrated by the figure where at $400^{\circ} \mathrm{C}$, the thermal radiation emitted by surface $\mathrm{C}$ is more than 2.5 times the radiation of surface $\mathrm{A}$. 


\section{THEORY}

Figure 2 illustrates the basic theory of the experimental apparatus. If $A_{1}$ is the experimental sample and $\mathrm{A}_{2}$ represents the surroundings, then the radiosity is related to the blackbody emissive power and the irradiation of surface $A_{1}$ by,

$$
J_{1}=\epsilon_{1} E_{b 1}+\rho_{1} G_{1}
$$

Since $\rho_{1}=\left(1-\alpha_{1}\right)$ and if the surface $A_{1}$ is opaque and the system is either gray or close enough to thermal equilibrium so that $\alpha=\epsilon$, then Eq. (1) becomes,

$$
\begin{gathered}
J_{1}=\epsilon_{1} E_{b 1}+\left(1-\epsilon_{1}\right) G_{1} \quad \text { or, } \\
G_{1}=\frac{J_{1}-\epsilon_{1} E_{b 1}}{\left(1-\epsilon_{1}\right)}
\end{gathered}
$$

However, the net heat flow from surface $A_{1}$ is the difference between the radiosity and irradiation.

$$
\frac{\mathrm{Q}_{1}}{\mathrm{~A}_{1}}=\mathrm{J}_{1}-\mathrm{G}_{1}
$$

Combining Eqs. (2) and (3) yields the following for the surface heat flux from $A_{1}$,

$$
\mathrm{Q}_{1}=\frac{\mathrm{E}_{\mathrm{b} 1}-\mathrm{J}_{1}}{\left(1-\epsilon_{1}\right) / \mathrm{A}_{1} \epsilon_{1}}
$$

A similar relationship may be developed for surface $\mathrm{A}_{2}$ by the same methodology. The denominator of Eq. (4) can be considered a surface resistance to heat transfer. Consider now the exchange of radiant energy between two surfaces $A_{1}$ and $A_{2}$. The total radiation which leaves surface 1 and reaches surface 2 is $J_{1} A_{1} F_{12}$, and the total energy which leaves surface 2 and reaches surface 1 is $J_{2} A_{2} F_{21}$. Thus, the net radiant energy interchange between the two surfaces in terms of radiosity is $Q_{1-2}=J_{1} A_{1} F_{12}-J_{2} A_{2} F_{21}$, where $F_{12}$ is the angle factor between 1 and 2. Since $A_{1} F_{12}=A_{2} F_{21}$, this relation can be rewritten as follows, 


$$
\mathrm{Q}_{1-2}=\frac{\mathrm{J}_{1}-\mathrm{J}_{2}}{1 /\left(\mathrm{A}_{1} \mathrm{~F}_{12}\right)}=\frac{\mathrm{J}_{1}-\mathrm{J}_{2}}{1 /\left(\mathrm{A}_{2} \mathrm{~F}_{21}\right)}
$$

The denominator of Eq. (5) can be considered a spatial resistance to heat transfer. Using Eqs. (4) and (5), one can solve for the overall net heat transfer between surfaces $A_{1}$ and $A_{2}$ as shown below.

$$
\mathrm{Q}_{1-2}=\frac{\mathrm{E}_{\mathrm{b} 1}-\mathrm{E}_{\mathrm{b} 2}}{\frac{1-\epsilon_{1}}{\mathrm{~A}_{1} \epsilon_{1}}+\frac{1}{\mathrm{~A}_{1} \mathrm{~F}_{12}}+\frac{1-\epsilon_{2}}{\mathrm{~A}_{2} \epsilon_{2}}}
$$

However, if $\mathrm{F}_{12}=1, \mathrm{~A}_{1}<<\mathrm{A}_{2}$, and $\epsilon_{2}=1$,

$$
\mathrm{Q}_{1-2}=\mathrm{A}_{1} \epsilon_{1} \sigma\left(\mathrm{T}_{1}^{4}-\mathrm{T}_{2}^{4}\right)
$$

or

$$
\epsilon_{1}=\frac{\mathrm{Q}_{1-2}}{\mathrm{~A}_{1} \sigma\left(\mathrm{T}_{1}^{4}-\mathrm{T}_{2}^{4}\right)}
$$

Equation (7) is the operative equation of the experimental apparatus. It contains the following assumptions:

1. The thermal radiation emitted, absorbed and reflected in the system is diffuse.

2. The area of the sample is "small" compared to the area of the surroundings. Physically this means that only an insignificant amount of radiation emitted by $A_{1}$ returns to $A_{1}$ from $A_{2}$. Also, if $A_{2}$ is "black" ( $\left.\epsilon_{2}=1\right)$ as described below, then Eq. (6) becomes Eq. (7).

3. Kirchoff's law holds for the sample $\left(\alpha_{1}=\epsilon_{1}\right)$ which requires either that $T_{2} \approx T_{1}$ or the sample is gray, i.e., $\epsilon_{1}$ is not a function of wavelength.

Of all of the above assumptions, the effect of the use of Kirchoff's law is the most difficult to quantify. Since the incoming radiation is small compared to the radiation from the test sample, it is not absolutely necessary to use Kirchoff's law as is illustrated in Eq. (2). The discussion that 
follows will illustrate the maximum errors that can be incurred by neglecting Kirchoff's law (i.e., by neglecting incoming radiation). If the enclosure radiation on the test sample is neglected, then Eq. (7) becomes,

$$
\epsilon_{1}=\frac{\mathrm{Q}_{1-2}}{\mathrm{~A}_{1} \sigma \mathrm{T}_{1}^{4}}
$$

Thus, the fractional difference between Eq. (7) and Eq. (8) is,

$$
\frac{\epsilon_{1, \text { Eq } 7}-\epsilon_{1, \text { Eq } .8}}{\epsilon_{1, \text { Eq. } 7}}=\left(T_{2} / T_{1}\right)^{4}
$$

For an enclosure temperature of $\mathrm{T}_{2}=300 \mathrm{~K}$, Table 1 lists these differences.

Table 1

Emissivity Differences With and Without Kirchoff's Law

\begin{tabular}{|c|c|}
\hline$T_{1}(\mathrm{~K})$ & Difference (\%) \\
\hline 573 & 7.5 \\
\hline 673 & 3.9 \\
\hline 773 & 2.3 \\
\hline 823 & 1.8 \\
\hline 873 & 1.4 \\
\hline 973 & 0.9 \\
\hline 1073 & 0.6 \\
\hline 1173 & 0.4 \\
\hline 1273 & 0.3 \\
\hline
\end{tabular}

The maximum error incurred by the misuse of Kirchoff's law (i.e., assuming $\alpha_{1}=\epsilon_{1}$ ) is bounded by the error incurred by neglecting incoming radiation to the sample altogether. Assuming that the neglect of incoming radiation is an upper bound on any errors occasioned by using Kirchoff's law $\left(\alpha_{1}=\epsilon_{1}\right)$, these errors are illustrated in Table 1 . For $T_{1} \geq 800 \mathrm{~K}$, this would cause maximum errors of less than $2 \%$. Errors at other temperatures can be estimated from Table 1 or Eq. (9). Also, the 
measured values of $\epsilon_{1}$ from Eq. (7) would be equal to or slightly higher than the actual emissivities, depending on the fidelity of the experiment to the requirements of Kirchoff's law (i.e., $\alpha_{1}=\epsilon_{1}$ ). The actual errors are expected to be less than the values in Table 1 over the complete range of $T_{1}$. In the lower temperature range, $300<\mathrm{T}_{1}<500 \mathrm{~K}$, the conditions approach those for which Kirchoff's law is valid.

\section{TEST SAMPLE PREPARATION AND EXPERIMENTAL APPARATUS}

Samples were prepared from Inconel-718 alloy material by successively rolling and annealing bar stock to a material thickness of $0.005 \mathrm{inch}(0.127 \mathrm{~mm})$. Strips of this material were cut to a rough size of six inches $(152.4 \mathrm{~mm})$ long by 0.125 inch $(3.175 \mathrm{~mm})$ wide using tin snips. A fixture was designed and fabricated to allow the long edges of the samples to be surface ground parallel and to a uniform width. Final strip widths were nominally 0.105 inch $(2.667 \mathrm{~mm})$. Sample thickness and width dimensions were measured with a calibrated micrometer to a precision of \pm 0.0001 inch $( \pm 0.0025 \mathrm{~mm})$. All other dimensions, such as strip heated length and wire positions, were measured with a calibrated dial-indicating caliper to a precision of \pm 0.0005 inch $( \pm 0.0127 \mathrm{~mm})$. Strips were instrumented with Type-S (Pt/Pt-10\%Rh) thermocouples fabricated from 0.005 inch $(0.127 \mathrm{~mm})$ diameter wire. The Type-S wires were individually spot welded to the strips by a capacitive discharge technique, spanning the centerline in close proximity to each other. This ensured that the thermocouple junction mass was as small as possible and as closely coupled to the strip as possible. Three thermocouples were attached to each strip with one at the center of the long dimension of the strip, and the other two displaced 0.75 inches $(19.05 \mathrm{~mm})$ in either direction. Two 0.005 inch $(0.127$ $\mathrm{mm}$ ) diameter Pt wire potential taps were also spot welded to the strips on the strip centerline displaced 0.50 inch $(12.7 \mathrm{~mm})$ in either direction from the center thermocouple. Thermocouple and potential tap attachments were made prior to oxidation of the strips to ensure a high quality bond with the substrate. After cleaning with solvents to remove any oils or fingerprints, samples were then oxidized in air to their prescribed conditions in a specially-prepared fused quartz fixture. This fixture supported the strip in such a way as to protect the attached leads, and to guarantee that all sides of the strip received uniform exposure to the furnace conditions. Figure 3, a schematic of a sample whose emissivity is to be measured, illustrates the actual experimental measurement techniques. The sample is heated by passing $60 \mathrm{~Hz}$ alternating current, $i$, down the long axis. The voltage drop, $\Delta \mathrm{V}$, is measured across the measured sample length, $\ell$. The sample area of interest is taken as $2 \ell w$ (the area used in the actual calculations also includes the area contributed by the sample edges). The center temperature is taken as the sample temperature, and the other two measurements made to ensure that the sample is isothermal across $\ell$. Rewriting Eq. (7) in terms of the variables in Figure 3 yields the following expression for the emissivity.

$$
\epsilon=\frac{i \Delta V}{2 \ell w \sigma\left(T_{1}^{4}-T_{2}^{4}\right)}
$$


The apparatus is illustrated schematically in Figure 4 and described in detail below. The system was designed and constructed drawing on guidance gained from References [4-7]. A vacuum chamber was fabricated from eight-inch diameter stainless steel tube, seven inches long and painted flat black on its interior. This tube was equipped with eight-inch Con-flat type flanges on each end. One end was closed with a blank flange and copper gasket. The blank flange formed the floor of the vacuum chamber. Midway up the side of the vessel, a 1.5 inch diameter nipple was welded in radially and equipped with a 1.5 inch Con-flat type flange for connection to the vacuum system. The upper eightinch flange carried several vacuum feedthroughs equipped with terminals appropriate for the connection of Type-S thermocouples and also connection of the potential taps. The center of the upper eight-inch flange incorporated a 1.5 inch Con-flat type machining detail to allow the placement of the sample holder into the vacuum space. The sample holder was fabricated on the end of a high-current vacuum feedthrough and held the sample on the vertical centerline of the vacuum chamber. A copper fixed-grip was attached to the short leg of the feedthrough, and a spring loaded floating-grip was mounted to the long leg. Upon installation of the sample in the vacuum chamber, care was taken to insure that the sample was rotated such that the sample faces did not view either the 1.5 inch vacuum connection or the long high-current lead. The upper eight-inch flange was sealed with a Viton quad ring gasket to facilitate repeated assembly and disassembly. The chamber was pumped by an oil diffusion pump equipped with a liquid nitrogen cold trap, and backed by a rotary vane mechanical roughing pump. This system routinely achieved vacuum in the low $10^{-6}$ Torr range. Power was provided to heat the sample by a high current, low voltage, variable AC transformer. A Hewlett Packard 3455A digital voltmeter and Hewlett Packard scanner were used for all voltage measurements, both $\mathrm{AC}$ and DC. Both instruments were controlled and data was acquired via IEEE-488 bus communication to a personal computer. Current was determined by using the above instrumentation to measure the voltage drop across a calibrated multi-range selectable precision shunt in series with the sample. Measurements of the three sample thermocouples, the sample voltage drop at the potential taps, the total sample voltage drop, the shunt resistor voltage drop and the vacuum vessel wall temperature were made once every 10 seconds during periods of data acquisition. All data were imported into Microsoft Excel spreadsheets. Calculations in the spreadsheets incorporated the current shunt correction factors, calculation of sample surface area based on an individual sample's measurements, and thermal expansion effects as a function of temperature.

\section{MEASUREMENT ERRORS}

Equation (7), the operative equation of the apparatus, can be utilized to approximately predict the experimental errors of the emissivity measurements. Assuming that $\mathrm{Q}_{1-2}$ and $\mathrm{A}_{1}$ can be measured with negligible error, then the emissivity errors caused by errors in $T_{1}$ and $T_{2}$ can be written as,

$$
\frac{\Delta \epsilon}{\epsilon}=\frac{4 \Delta \mathrm{T}_{1}}{\mathrm{~T}_{1}}+\frac{4 \Delta \mathrm{T}_{2}}{\mathrm{~T}_{2}}
$$

The most serious error in measuring the sample temperature, $\mathrm{T}_{1}$, occurs from heat flow down the 
thermocouple wire due to conduction down the wire and radiation from the wire surface. Utilizing the solution of a radiating wire [8] and the temperature depression on the sample at the location where the wire is attached [9], the first term on the RHS of Eq. (11) was estimated to be $1.7 \%$ and the second term $1.3 \%$. Thus, the overall measurement error of the emissivity is estimated to be $3 \%$.

\section{EXPERIMENTAL RESULTS AND DISCUSSION}

As previously mentioned, the emissivity samples were Inconel-718. Table 2 lists the constituents for this particular alloy.

Table 2

Constituents of Inconel-718 [10]

\begin{tabular}{|c|c|}
\hline Constituent & \% of Weight \\
\hline $\mathrm{Ni}$ & 52.5 \\
$\mathrm{Cr}$ & 19.0 \\
$\mathrm{Fe}$ & 18.5 \\
$\mathrm{Nb}$ & 5.2 \\
$\mathrm{Mo}$ & 3.0 \\
$\mathrm{Ti}$ & 0.8 \\
$\mathrm{Al}$ & 0.6 \\
$\mathrm{Si}$ & 0.2 \\
$\mathrm{Mn}$ & 0.2 \\
\hline
\end{tabular}

Ten experimental runs were made on Inconel-718 samples under various surface oxidation and surface temperature conditions. Table 3 lists these temperature and oxidation conditions for nine of the runs (002 and 003 and 005 to 011 ). Run number 001 was for an unoxidized sample in an "as rolled" condition from the manufacturer. Run number 004 was an oxidation in a $\mathrm{CO}_{2}$ atmosphere which is not relevant to the present investigation. The oxidations were carried out within the enclosure at atmospheric pressure by maintaining the surface temperatures for the indicated times.

Table 3

Run Numbers for Various Pre-Test Oxidation Times and Temperatures

\begin{tabular}{|c|c|c|c|}
\hline \multirow{2}{*}{$\begin{array}{c}\text { Oxidation Times } \\
\text { (minutes) }\end{array}$} & \multicolumn{3}{|c|}{ Oxidation Temperature $\left({ }^{\circ} \mathbf{C}\right.$ ) } \\
\cline { 2 - 4 } & $\mathbf{1 0 0 0}$ & $\mathbf{1 1 0 0}$ & $\mathbf{1 1 4 2}$ \\
\hline 15 & 011 & 006 & 009 \\
30 & 003 & 007 & 005 \\
60 & 002 & 008 & 010 \\
\hline
\end{tabular}


Figure 10c (which is discussed out of order) illustrates the difficulty encountered in measuring emissivities when the surface temperature exceeded $1000^{\circ} \mathrm{C}$. Above this temperature, the thermocouples began to give anomalous readings for unknown causes. This anomaly was investigated further by a separate experiment. In this experiment, a thermocouple was welded to a small piece of Inconel-718 and then wrapped around the standard thermocouple tube. The thermocouples were then placed in a furnace at atmospheric pressure and a comparison was made of the two measured temperatures. The results are shown in Figure 5 which shows the difference between the two measured temperatures as a function of the measured standard temperature. Under these experimental conditions, an anomaly in the Seebeck coefficient of the spot-welded thermocouple can be clearly seen which has a maximum effect at approximately $1000^{\circ} \mathrm{C}$. It is believed that the same anomalous condition appeared in the results in [4] which could explain the transient effects at constant input power which the authors reported. Because this anomaly under vacuum conditions always appeared at temperatures above $1000^{\circ} \mathrm{C}$, it was decided to only report measured emissivities up to $1000^{\circ} \mathrm{C}$ as shown in the following figures. Emissivities will only increase with further increasing temperatures.

Figure 6 shows the emissivity vs. surface temperature for the Inconel at "as rolled" conditions. The results indicate a "moderately" low emissivity which increases from a value of approximately 0.20 at a surface temperature of $200^{\circ} \mathrm{C}$ to 0.33 at a temperature of $1000^{\circ} \mathrm{C}$.

Figures 7a-c show the emissivity vs. surface temperature curves for an oxidizing surface temperature of $1000^{\circ} \mathrm{C}$. Several phenomena can be can be seen from these data: oxidation increases the emissivity by a significant amount as was noted earlier (Figure 1) and is evident by comparing Figures 7a-c with Figure 6. Also, there is an appreciable increase of emissivity with surface temperature.

Figure 8 plots the data of Figures 7a-c on a single graph where it is easier to examine the effect of oxidation time. From Figure 8, the 30-minute oxidation sample has a lower emissivity than the 15minute sample. On the other hand, the 60 -minute sample has a greater emissivity than the other two. Thus, at least for these data (oxidized at $1000^{\circ} \mathrm{C}$ ), there does not seem to be a simple relation between emissivity and oxidation time. This same result will again be apparent in the discussions of the tests which were pre-oxidized at $1100^{\circ} \mathrm{C}$ and $1142^{\circ} \mathrm{C}$.

Figures $9 a-c$ present the surface temperature vs. emissivity data when the oxidation occurs at a surface temperature of $1100^{\circ} \mathrm{C}$. There are some striking differences between these data and those for which the oxidation occurred at a surface temperature of $1000^{\circ} \mathrm{C}$ (Figures $7 \mathrm{a}-\mathrm{c}$ ). For the low temperature emissivity measurements $\left(200 \leq \mathrm{T}_{\mathrm{SUR}} \leq 800^{\circ} \mathrm{C}\right)$ the emissivities for samples with $1000^{\circ} \mathrm{C}$ oxidation temperatures are significantly lower than the emissivities for samples with $1100^{\circ} \mathrm{C}$ oxidation temperatures. For example, at a surface temperature of $300^{\circ} \mathrm{C}$, the 15 minute$1100^{\circ} \mathrm{C}$ oxidation temperature emissivity is approximately equal to 0.85 while for the 15 minute$1000^{\circ} \mathrm{C}$ oxidation temperature, the emissivity is equal to 0.65 , a decrease of $31 \%$. Thus, the oxidation temperature has a significant influence on the emissivity in the "low temperature range."

It will also be noted in examining Figures 9a-c that emissivity measurements were made with both 
ascending and descending surface temperatures. For oxidation times of 15 and 30 minutes, both ascending and descending data show reasonable agreement. However, for the oxidation time of 60 minutes the descending data are lower than the ascending data. One possible explanation for this behavior is that the thicker oxidized layer at the higher oxidation time is more sensitive to surface spalling as the surface area expands and contracts with temperature. Although the thermal expansion area change was accounted for in the emissivity calculations, it was not possible to visually examine the oxidized surface conditions for spalling while the surface area was changing with temperature. However, some black powdery oxide was found in the vacuum chamber after the tests which supports this contention. As the sample length and width dimensions change with temperature from 200 to $1000^{\circ} \mathrm{C}$, the linear dimensions of the samples are calculated to increase by approximately $1.3 \%$.

Figures $10 \mathrm{a}-\mathrm{c}$ present the emissivity vs. temperature data when the oxidation temperature was $1142^{\circ} \mathrm{C}$. In general, the emissivity-temperature data approximately agree with the data for an oxidation temperature of $1100^{\circ} \mathrm{C}$. Also, once again as seen in Figure 9c, the descending data for an oxidation time of 60 minutes are lower than the ascending data as was the case for the oxidation temperature of $1100^{\circ} \mathrm{C}$.

Table 4 presents the maximum measured emissivities for each of the experiments as a function of the pre-test oxidation times and temperatures. These maxima in the emissivity were chosen from the experimental data for each experiment over the test temperature range up to $1000^{\circ} \mathrm{C}$ and are, as a rule, the measured emissivities at $1000^{\circ} \mathrm{C}$. It is evident from the table that the sample emissivity increases with pre-test oxidation temperature from $1000^{\circ} \mathrm{C}$ to $1100^{\circ} \mathrm{C}$, but that there is little additional increase, if any, as the pre-test oxidation temperature increases to $1142^{\circ} \mathrm{C}$. There is no apparent trend in the emissivities as the time of pre-oxidation is varied from 15 minutes to 60 minutes. This is fortunate in so far as application of the test results to a heat transfer transient does not appear to involve a significant transient in the emissivity itself.

Table 4

Maximum Emissivities for Various Pre-Test Oxidation Times and Temperatures ${ }^{*}$ Over the Test Temperature Range up to $1000^{\circ} \mathrm{C}$

\begin{tabular}{|c|c|c|c|}
\hline \multirow{2}{*}{$\begin{array}{c}\text { Oxidation Times } \\
\text { (minutes) }\end{array}$} & \multicolumn{3}{|c|}{ Oxidation Temperature $\left({ }^{\circ} \mathbf{C}\right)$} \\
\cline { 2 - 4 } & $\mathbf{1 0 0 0}$ & $\mathbf{1 1 0 0}$ & $\mathbf{1 1 4 2}$ \\
\hline 15 & 0.86 & 0.90 & 0.89 \\
30 & 0.84 & 0.90 & 0.91 \\
60 & 0.88 & 0.89 & 0.91 \\
\hline
\end{tabular}

*The peak emissivity for the non-oxidized sample was 0.33 . 


\section{CONCLUSIONS}

Total hemispherical emissivities were measured for Inconel-718 under a variety of surface temperatures and surface oxidation conditions. The following results were obtained:

1. Unoxidized Inconel-718 in an "as received" condition had emissivities that increased from approximately 0.24 to 0.33 over a surface temperature range $200 \leq \mathrm{T} \leq 1000^{\circ} \mathrm{C}$.

2. When the surface was oxidized in air at atmospheric pressure with temperatures of $1000^{\circ} \mathrm{C}$, $1100^{\circ} \mathrm{C}$ and $1142^{\circ} \mathrm{C}$, the emissivity increased slightly with temperature in the approximate range from 0.85 to 0.90 over the temperature range from $200 \leq \mathrm{T} \leq 1000^{\circ} \mathrm{C}$.

3. No conclusive trend of emissivity was observed as a function of oxidation time (15-60 minutes) at a given oxidation temperature.

4. Measurements made at the highest oxidation time at increasing surface temperatures were greater than those repeated at decreasing surface temperatures. One possible reason for this could be the spalling of the oxide layer as the surface changed its dimensions with temperature. This behavior would, of course, be self-correcting in an oxidizing environment while these experiments were, by necessity, performed in a vacuum.

The accident analyses presented in the APT PSAR rely upon emissivity information taken from [2] for stably-oxidized Inconel-718. Reference 2 suggests an emissivity of 0.75 at $250^{\circ} \mathrm{C}$ increasing linearly to 0.85 at $810^{\circ} \mathrm{C}$; no values are given for higher temperatures, thus APT assumed the emissivity to remain constant at 0.85 for temperatures in excess of $810^{\circ} \mathrm{C}$. It is clearly stated in [2], however, that these values are not based on experimental data but have been derived on the basis of the observed general behavior of the emissivity of Ni-Cr-Fe alloys. In Table 4, it is clearly evident that the emissivities measured in this study closely approached or exceeded 0.85 at $1000^{\circ} \mathrm{C}$ (in only one case, EMIS-003, the measured value is 0.84 ). Examination of Figures 9 and 10 clearly demonstrates that for samples which were pre-oxidized at $1100^{\circ} \mathrm{C}$ and higher, the measured data always exceed the values from [2]. By using values for the emissivity of Inconel-718 from [2] that are less than the measured values presented here, the APT PSAR accident calculations over predict the target temperatures, and thus, the calculations are conservative. 


\section{REFERENCES}

1. Touloukian, Y. S. and D. P. DeWitt, Thermal Radiative Properties-Metallic Elements and Alloys, v. 7 in the TPRC series, Thermophysical Properties of Matter, Plenum Publishing Corporation (1970).

2. Nuclear Systems Materials Handbook, TID-26666; Book 1, Part 1, Group 4, Section 5: Alloy-718, Thermal Emissivity (Stably Oxidized).

3. DeCorso, M. S. and R. L. Colt, "Measurement of Total Emissivities of Gas-Turbine Combuster Materials," ASME Paper No. 54-SA-26 (1954).

4. Richmond, J. C. and W. N. Harrison, "Equipment and Procedures for Evaluation of Total Hemispherical Emittance," Am. Ceramic Soc. Bull., 39(11), pp. 668-673 (1960).

5. Funai, A. I., "A Multichamber Calorimeter for High Temperature Emittance Studies," in Measurement of Thermal Radiation Properties of Solids, NASA SP-31, pp. 317-327 (1963).

6. Masuda, H. and M. Higano, "Measurement of Total Hemispherical Emissivities of Metal Wires by Using Transient Calorimetric Technique," J. Heat Transfer, 110, pp. 166-172 (1988).

7. Alaruri, S. D., L. Bianchini and A. Brewington, "Integrating Sphere Method for Determining the Effective Spectral Emissivity of Superalloys at High Temperatures Using a Single Wavelength Pyrometer," Optical Engineering, 35, pp. 2736-2742 (1996).

8. Brant, J. A., T, F. Irvine, Jr. and E. R. G. Eckert, "A Method of Measuring Total Hemispherical Emissivities at Low Temperatures - Results for Pure Iron from 300 to 500 Degrees Rankine," Proceedings of the 1960 Heat Transfer and Fluid Mechanics Institute, Mason, Reynolds and Vincenti, Eds., Stanford University Press, Stanford, California (1960).

9. Carslaw, H. S. and J. C. Jaeger, Conduction of Heat in Solids, 2nd Edition, p. 261, Oxford Science Publications (1986).

10. "High Temperature, High Strength Nickel Base Alloys," The International Nickel Company, Inc., 3rd Edition, p. 4 (1977). 


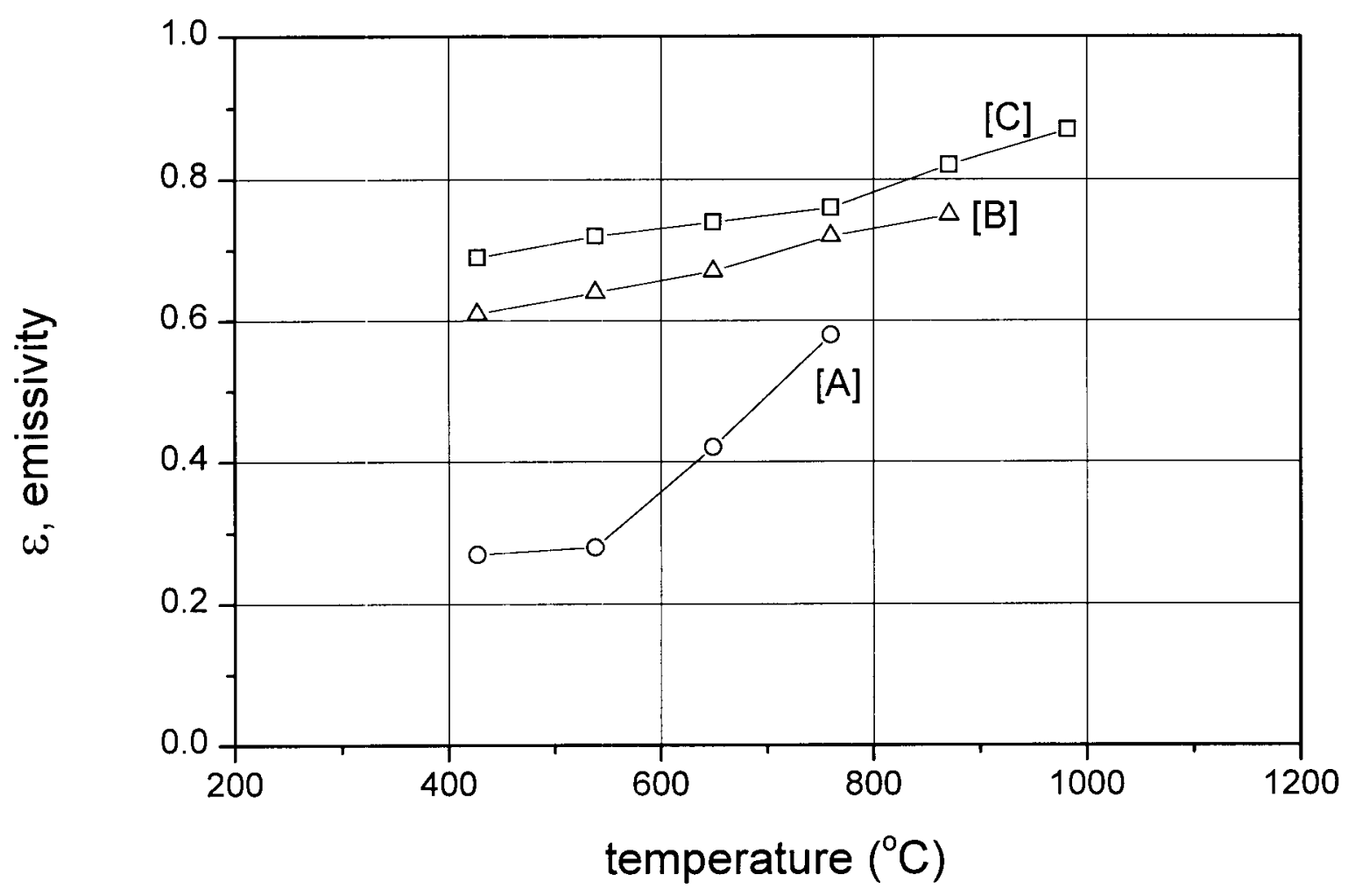

Figure 1. Variation of Total Hemispherical Emissivity of Inconel with Temperature and Surface Conditions [3]: [A]- As Rolled and Received, [B]-As Received and Oxidized for 15 Minutes at $815^{\circ} \mathrm{C}$, [C]-Sandblasted and Oxidized for 15 Minutes at $815^{\circ} \mathrm{C}$. 


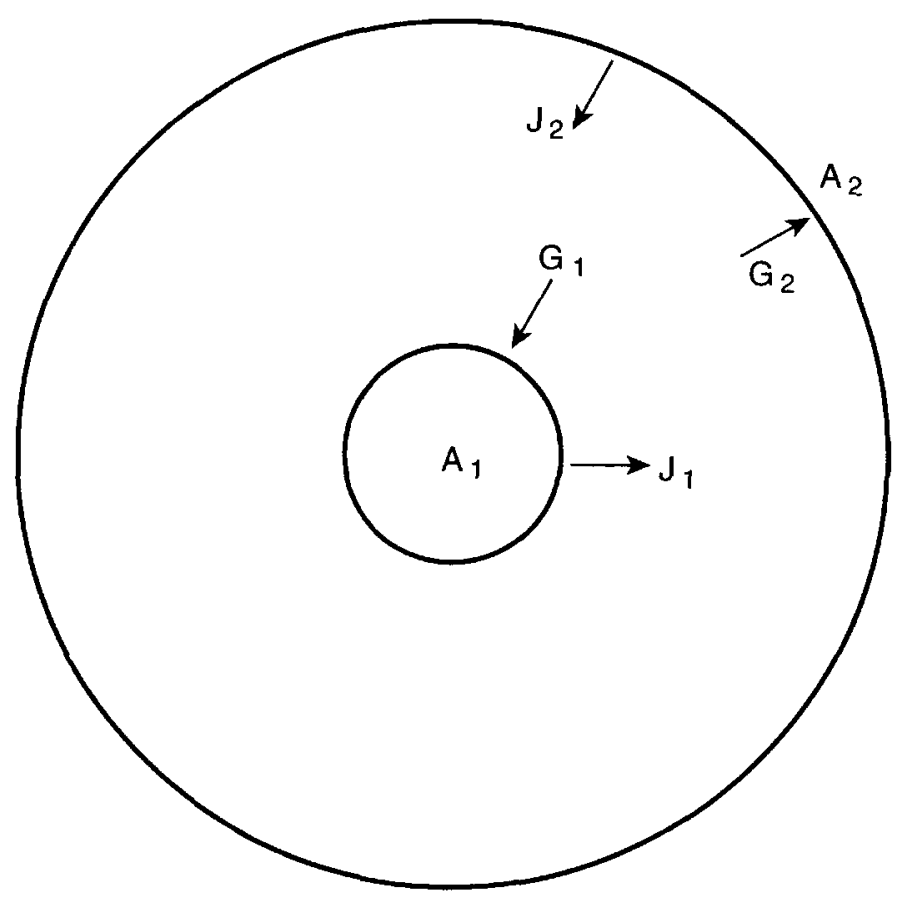

Figure 2. Radiation Between Two Surfaces where $\mathrm{G}=$ Irradiation, $\mathrm{J}=$ Radiosity. 


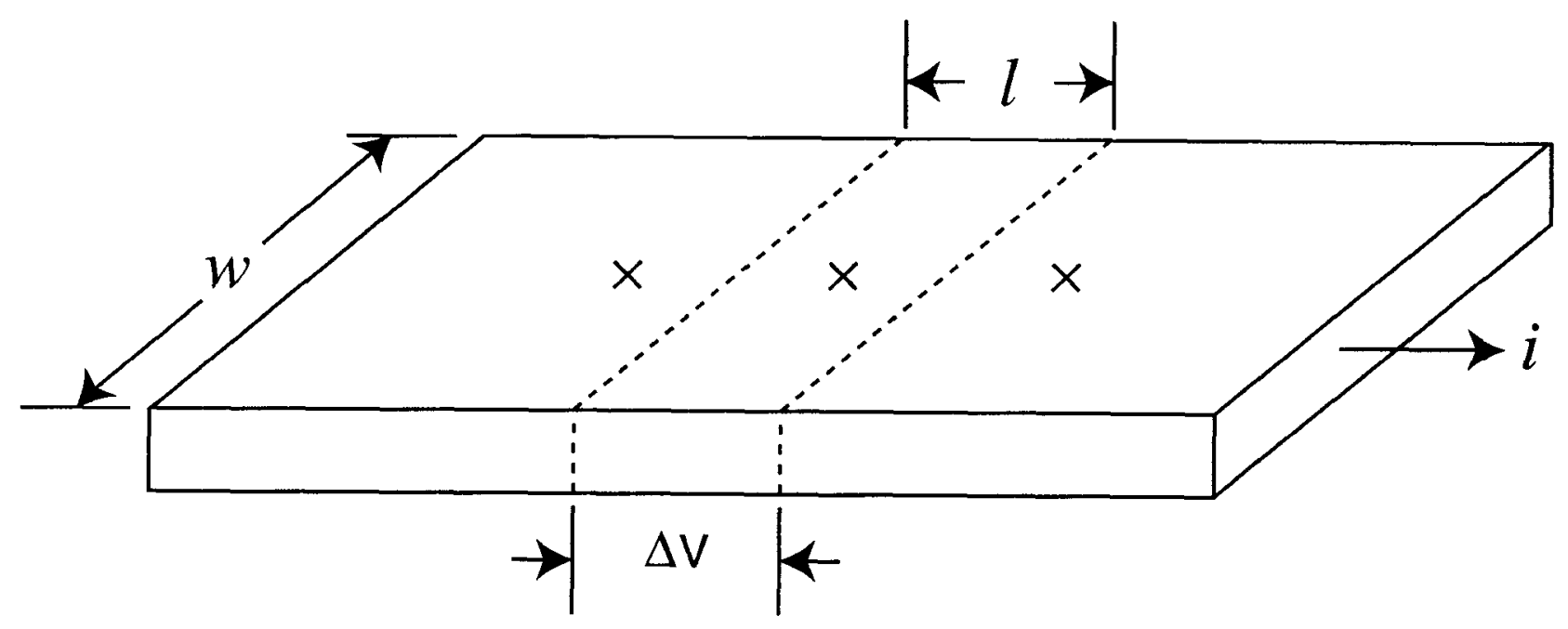

Figure 3. Schematic of Inconel-718 Sample: $\mathrm{x}=$ Thermocouple Wires. 


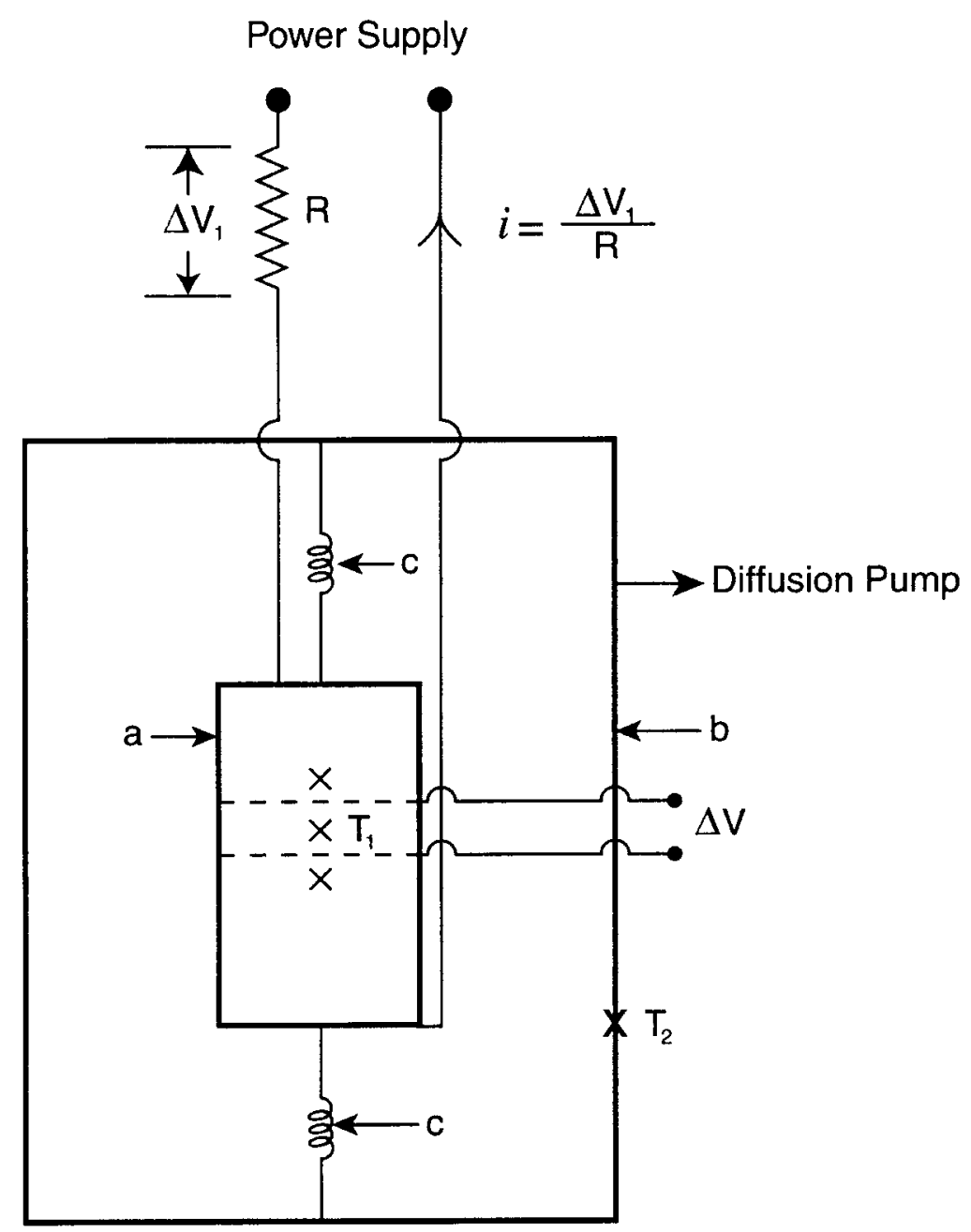

Figure 4. Schematic of Emissivity Measurement System: a- Inconel-718 Sample, b- Enclosure, c- Springs, $x$ - Thermocouple Wires. 


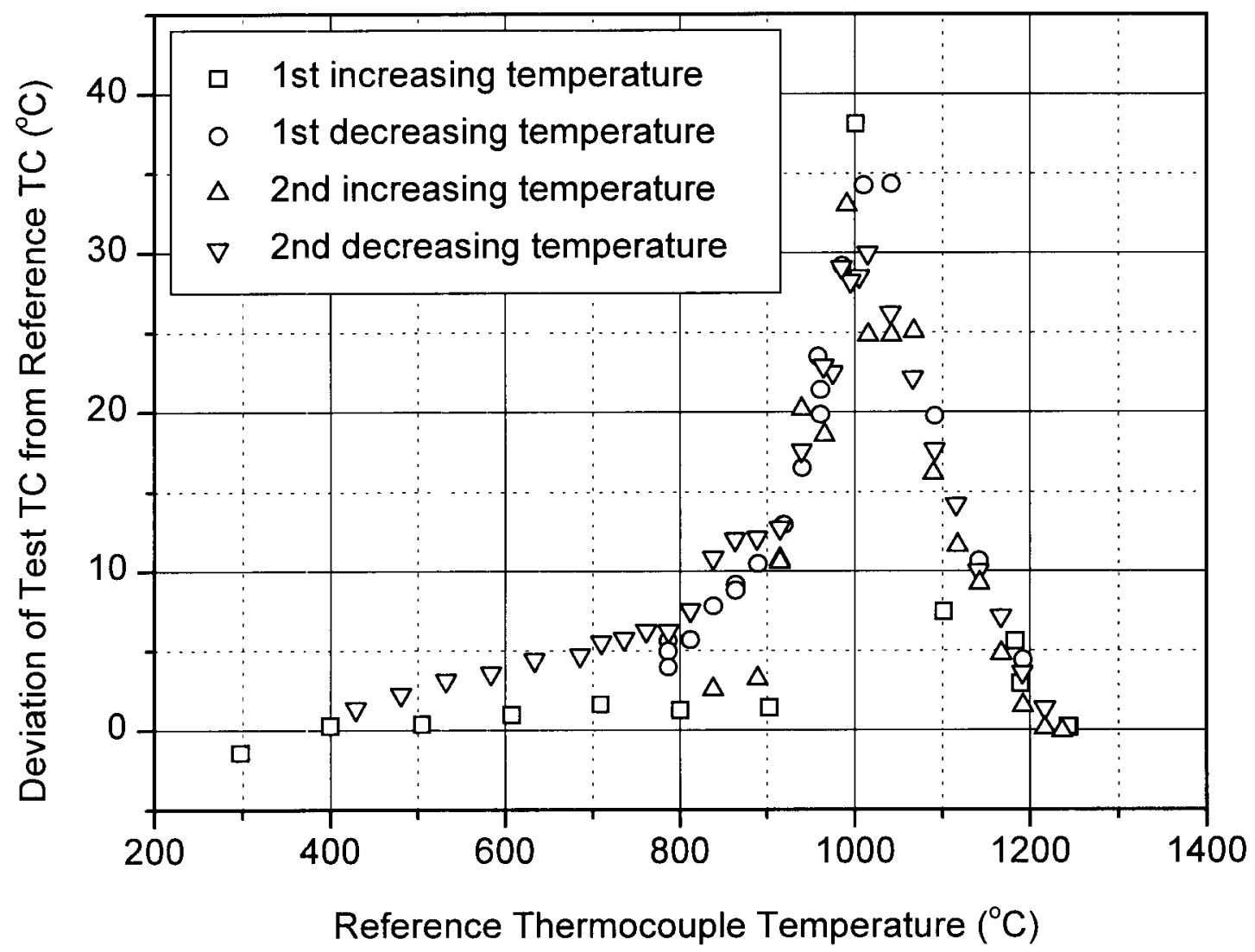

Figure 5. Temperature Difference Between Sample Thermocouple and Reference Thermocouple. 


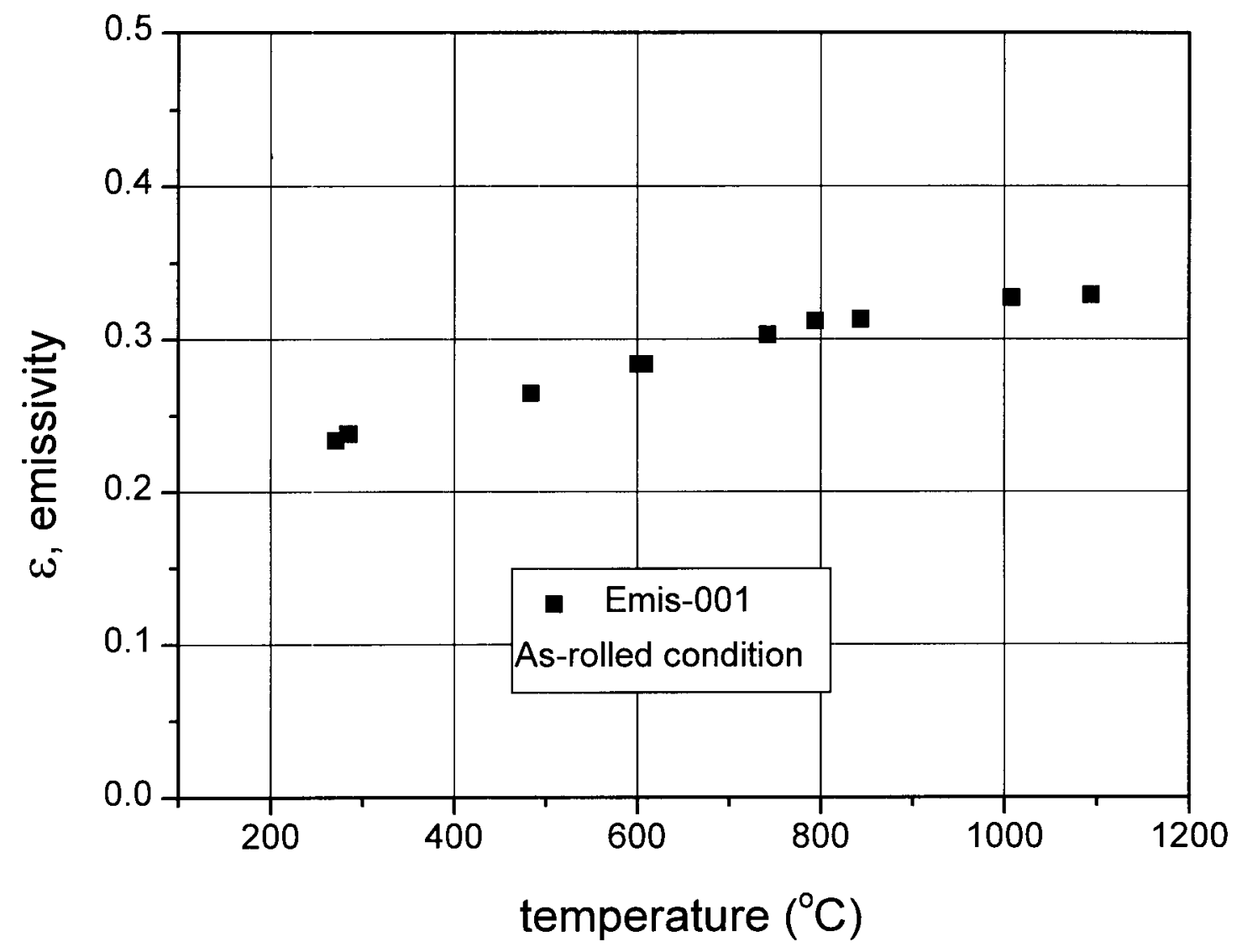

Figure 6. Total Hemispherical Emissivity vs. Sample Temperature for Inconel-718 (NonOxidized) in As-Rolled Condition. 

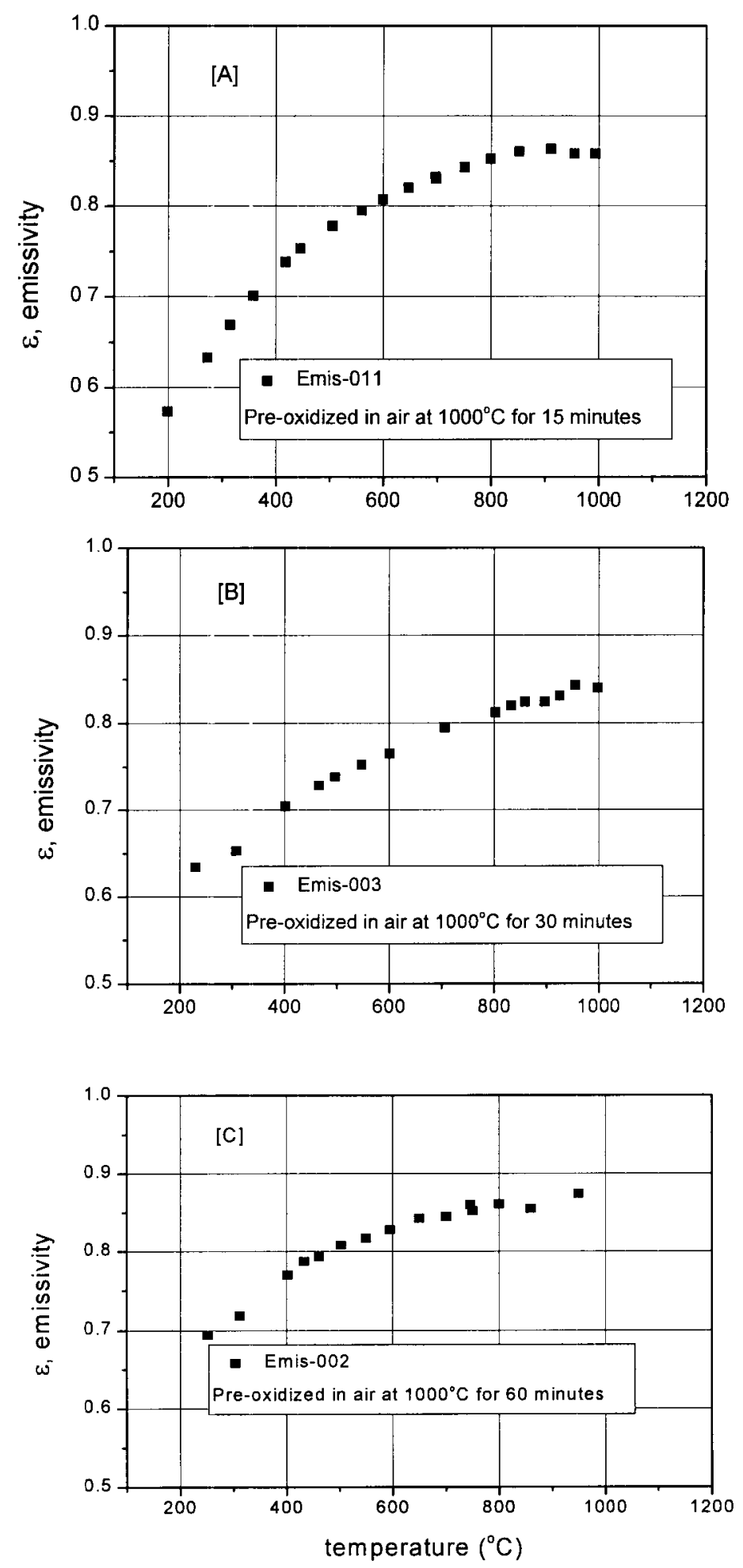

Figure 7. Total Hemispherical Emissivity vs. Sample Temperature for Inconel-718 Oxidized at $1000^{\circ} \mathrm{C}$ for 15 minutes [A], 30 minutes [B], 60 minutes [C]. 


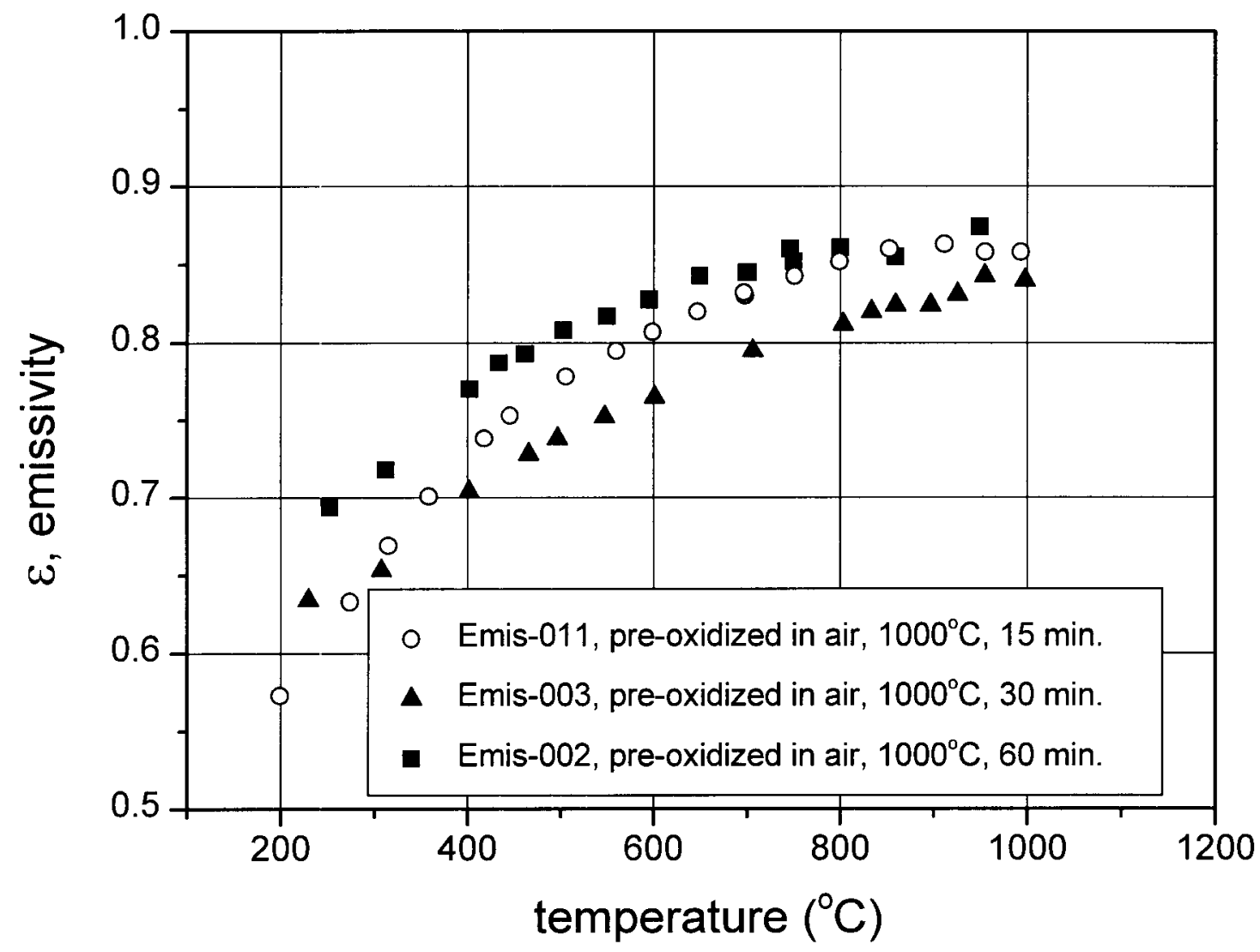

Figure 8. Comparison of Emissivities vs. Sample Temperature for Various Oxidation Times (Oxidized at $1000^{\circ} \mathrm{C}$ ). 

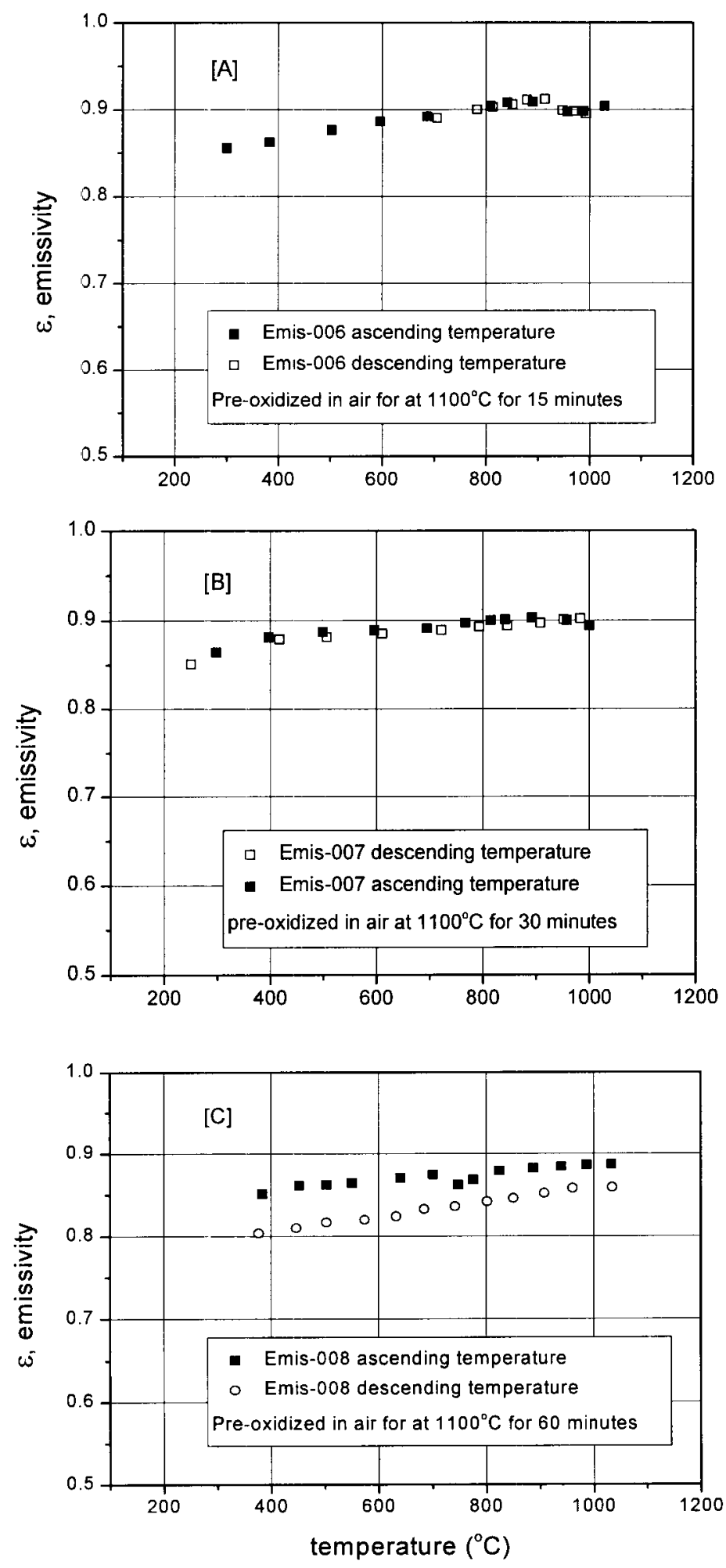

Figure 9. Total Hemispherical Emissivity vs. Sample Temperature for Inconel-718 Oxidized at $1100^{\circ} \mathrm{C}$ for 15 minutes [A], 30 minutes [B], 60 minutes [C]. 

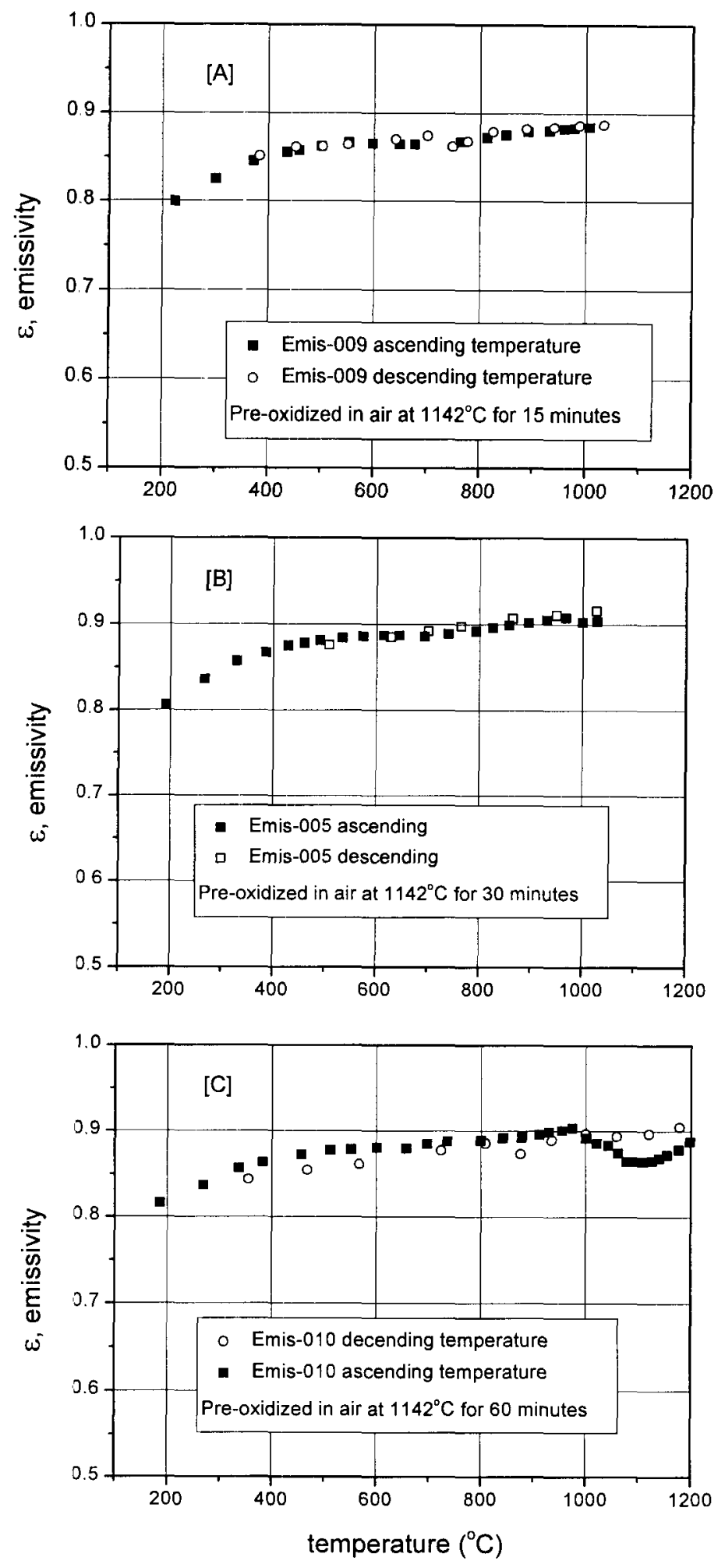

Figure 10. Total Hemispherical Emissivity vs. Sample Temperature for Inconel-718 Oxidized at $1142^{\circ} \mathrm{C}$ for 15 minutes $[\mathrm{A}], 30$ minutes $[\mathrm{B}], 60$ minutes $[\mathrm{C}]$. 